\title{
Prediction of landslide-induced debris flow hydrograph: the Atsumari debris flow disaster in Japan
}

\author{
H. Takaoka ${ }^{1}$, H. Hashimoto ${ }^{1}$, S. Ikematsu ${ }^{1} \&$ M. Hikida ${ }^{2}$ \\ ${ }^{I}$ Department of Civil Engineering, Kyushu University, Japan \\ ${ }^{2}$ Department of Civil Engineering, \\ Kagoshima National College of Technology, Japan
}

\begin{abstract}
Landslides sometimes occur on mountain slopes by heavy rains. Some of them change into debris flows and then move into mountain rivers. The debris flows erode the river bed and increase their discharge. Prediction of debris flow discharge becomes important for the simulation of flooding debris flows along the river. The purpose of the present study is to develop a prediction model of the landslide-induced debris flow hydrograph. This study is composed of three steps. First, we assume a transformation model of landslide into debris flow. Second, we calculate the development process of debris flow in the middle reach and determine the debris flow discharge. Finally, we simulate the flooding process of debris flow in the downstream reach.

Keywords: Atsumari River, debris flow, landslide, bed variation.
\end{abstract}

\section{Introduction}

There was a continuous heavy rain in Minamata City, Kumamoto Prefecture, Japan on July 20, 2003 (fig. 1). Especially, at the Atsumari River basin in the Minamata City as shown in fig. 2, the maximum hourly and accumulated rainfall was $91 \mathrm{~mm} / \mathrm{h}$ and $323 \mathrm{~mm}$, respectively (fig. 3). As a result, a large-scale of landslide occurred on the right-hand side slope of the Atsumari River. The landslide changed into debris flow. During the movement in the middle reach at steep slope, the debris flow eroded the river bed and bank and increased its flow discharge. In the downstream reach at mild slopes, the debris flow caused sediment deposition and moved over river bank. The debris flow broke several 
houses on the river bank and killed 15 people of residents along the river. The situation of the debris flow disaster in the Atsumari River is shown in Photo 1.

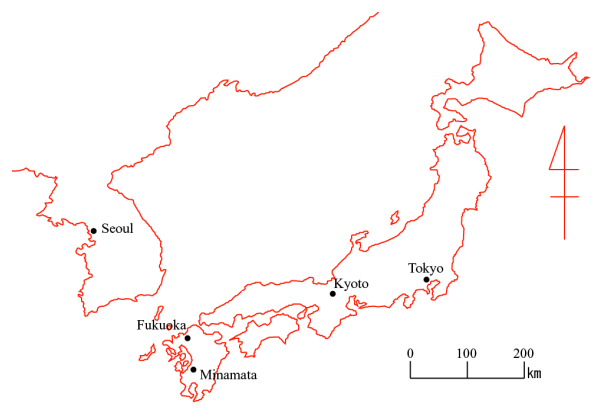

Figure 1: $\quad$ Location of Minamata City in Japan.

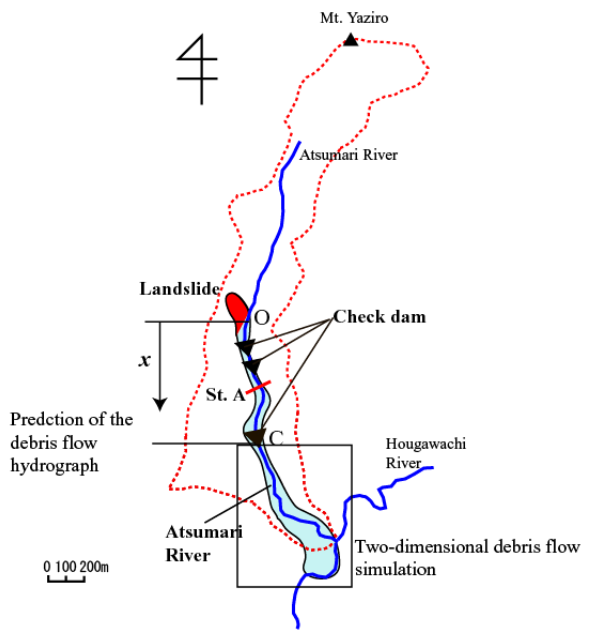

Figure 2: $\quad$ The Atsumari River basin.

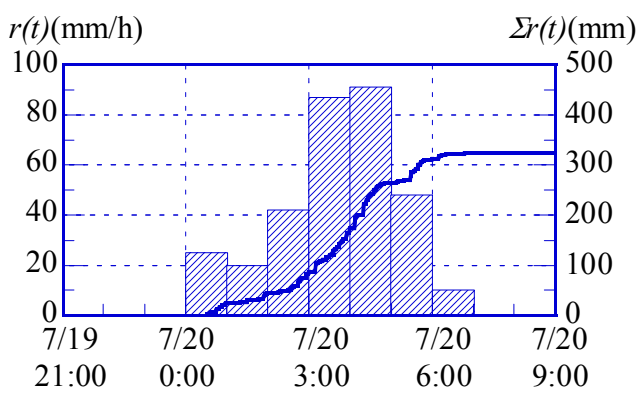

Figure 3: $\quad$ Rainfall measured near the Atsumari River. 


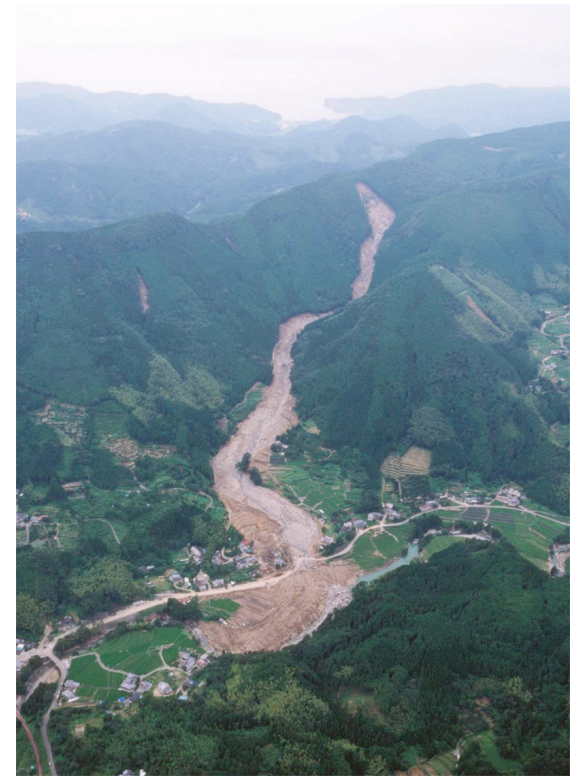

Photo 1: The debris flow disaster of the Atsumari River in Minamata City.

In order to measure such disaster, we have to predict the debris flow discharge by numerical simulation. There are some studies on the prediction of debris flow discharge.

Nakagawa et al. [1] \& [2] simulated the movement and deposition of the Harihara debris flow in Japan.

Hashimoto et al. [3] and Park \& Hashimoto [4] proposed a prediction model for debris-flow discharge on the basis of the discussion of river bed variation.

Satofuka [5] developed a 2-D hybrid debris flow model and applied to the Atsumari debris flow disaster. However, this model does not consider erosions of river bed and bank.

Takaoka et al. [6] derived river bed and bank erosion rate equations for mountain rivers. Using these equations, they attempted to simulate the Atsumari debris flow disaster (Takaoka et al. [7]). However, satisfactory discussion is not found on a transformation of landslides into debris flows.

The present study is an extension of the work of Takaoka et al. [7]. First, we assume a transformation model of landslide into debris flow. Second, we calculate channel variation in the middle reach and determine the flow discharge of the Atsumari debris flow. Finally, we make a two-dimensional simulation of debris flow in the downstream reach.

\section{Transformation model of landslide into debris flow}

From mass conservation of sediment, we obtain the relationship between landslide sediment volume $V_{s}$ and sediment discharge in initial debris flow $Q_{s 0}(t)$ : 


$$
\int_{0}^{T} Q_{s 0}(t) d t=V_{s}
$$

where $V_{s}=$ landslide sediment volume and $Q_{s 0}(t)=$ sediment discharge of initial debris flow.

Rewriting eqn (1), and denoting $Q_{s 0}(t) / V_{s}$ by $u(t)$, we have

$$
\int_{0}^{T} u(t) d t=1
$$

where $u(t)$ corresponds to a response function for the transformation from landslide into debris flow. Therefore, we can have the following relationship:

$$
\int_{-\infty}^{\infty} V_{s} \delta(t-\tau) u(\tau) d \tau=V_{s} u(t)=Q_{s 0}(t)
$$

where $\delta(t-\tau)$ is Dirac delta function. Landslide sediment volume $V_{s}$ can be regarded as the input of the system at time $t=\tau$ and sediment discharge $Q_{s 0}(t)$ as the output.

Since the evaluation of $u(t)$ is very difficult, we assume four cases as the response function. The response functions are shown in fig. 4. Cases A and B express the response function as rectangular waves, and Cases C and D as triangular.

$Q_{s 0}(t)$ is also expressed as

$$
Q_{s 0}(t)=C_{0} Q_{0}(t)
$$

where $C_{0}=$ sediment concentration and $Q_{0}(t)=$ the initial debris flow discharge.

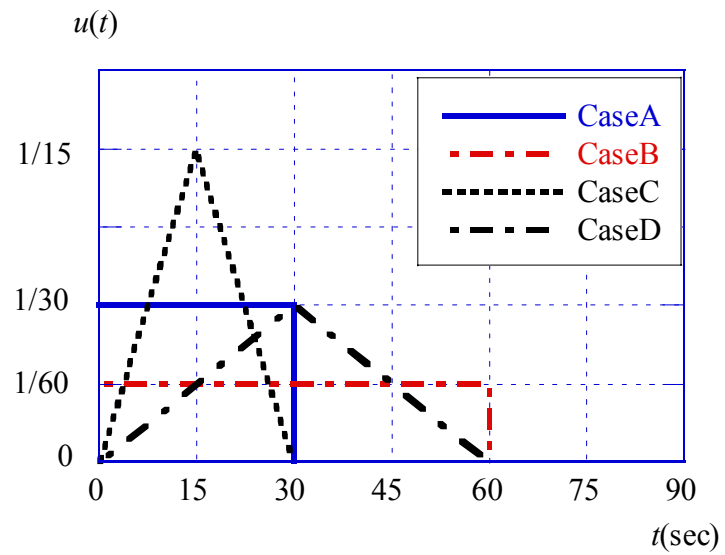

Figure 4: Assumed response functions.

\section{Prediction of the Atsumari Debris Flow Hydrograph}

Simulation is composed of two parts; one is prediction of hydrograph from the middle river reach and the other two-dimensional simulation of flooding debris flow on the deposition area. The former is the boundary condition for the latter. 
Therefore, using the hydrograph based on the river bed variation calculation, we can simulate numerically flooding debris flow. The study area is Atsumari River basin (fig. 2). There were three check dams in the Atsumari River.

We calculate river bed variation from the landslide position "O" to the most downstream check dam position "C", as shown in fig. 2. St. A indicates the position where we measured the channel cross section.

\subsection{Basic equations}

The cross section of the river reach is approximately trapezoidal and the angle of both side banks is 30 degrees. We assume that the river banks are eroded in lateral direction with constant angle of repose 30 degrees.

The equations of mass and momentum conservation govern the flow in the middle reach from station $\mathrm{A}$ to $\mathrm{C}$ :

the one-dimensional equation of motion

$$
\frac{\partial Q}{\partial t}+\frac{\partial v Q}{\partial x} \cos \theta=-g A \cos \theta\left[\frac{\partial(h+z \cos \theta)}{\partial x}\right]-\left(B+\frac{2 h}{\sin \beta}\right) \frac{v^{2}}{\phi^{2}}
$$

the continuity equation of sediment-water mixtures

$$
\frac{\partial\left(A+A_{s}\right)}{\partial t}+\frac{\partial Q}{\partial x} \cos \theta=q_{t i n}+h \frac{\partial B}{\partial t}
$$

the continuity equation of sediment

$$
\frac{\partial\left(C A+C_{*} A_{S}\right)}{\partial t}+\frac{\partial\left(C_{T} Q\right)}{\partial x} \cos \theta=q_{\sin }+C_{*} h \frac{\partial B}{\partial t}
$$

bed erosion rate equation

$$
\frac{\partial z}{\partial t}=-k_{b}\left(C_{T \infty}-C_{T}\right)^{p} v
$$

for $C_{T \infty}>C_{T}$ or

$$
\frac{\partial z}{\partial t}=k_{b}\left(C_{T}-C_{T \infty}\right)^{p} v
$$

for $C_{T \infty}<C_{T}$

lateral erosion rate equation

$$
\frac{\partial B}{\partial t}=k_{s} v
$$

where $\rho_{t}=$ density of the mixture; $Q=$ discharge of the mixture flow; $v=$ average velocity; $h=$ flow depth; $z=$ bed level; $B=$ river bed width; $A, A_{s}=$ cross section area of mixture flow and sediment; $\beta=$ bank slope angle; $\theta=$ river bed angle $\phi=$ nondimensional average velocity; $C=$ sediment concentration in the flow; $C_{T}=$ flux-averaged sediment concentration; $C_{T \infty}=$ equilibrium sediment concentration; $k_{b}=$ coefficient for bed erosion rate; $k_{s}=$ coefficient for lateral erosion rate; $q_{i n}, q_{\sin }=$ lateral inflow rate of the mixtures and sediment from the slopes (Park and Hashimoto [4]) and $x=$ distance measured in the flow direction from the upstream end of the river reach. We have the values of $k_{b}=0.01$ and $p$ $=0.7$ for eqn (8) and (9), and $k_{s}=0.01$ for eqn (10) (Takaoka et al. [6]). We can 
have the value of nondimensional average velocity $\phi=5$ (Takaoka et al. [8]). The schematic figure of channel cross section is shown in fig. 5 .

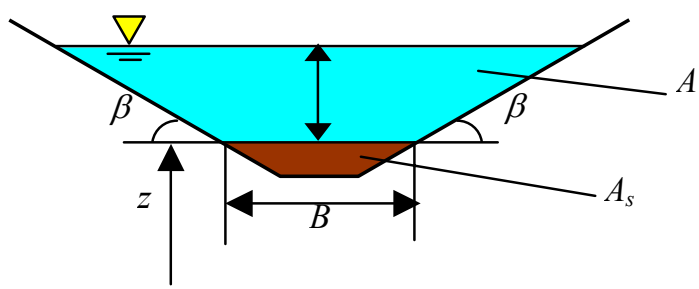

Figure 5: Schematic figure of cross section.

Denoting sediment and fluid density by $\sigma$ and $\rho$, we have $\rho_{\mathrm{t}}=\sigma C+\rho(1-C)$. In the discussion we assume sediment concentration profile uniform. Therefore we can have the relation of $C_{T}=C$. Indicating friction velocity by $u_{*}$, we have $\phi=$ $v / u *$.

Denoting equilibrium sediment discharge by $q_{s}$, we can express the equilibrium sediment concentration as

$$
C_{T \infty} \approx \frac{B q_{s}}{Q}
$$

We use the equilibrium sediment discharge formula for $q_{s}$ in eqn (11). The equilibrium sediment discharge formula proposed by Hashimoto et al. [9] \& [10] is appropriate for various kinds of sediment transport in steep rivers.

$$
\frac{q_{s}}{\sqrt{s g d^{3}}}=\frac{\bar{u}_{\delta}}{u_{*}} \tau_{*}^{3 / 2}\left(1-\frac{\tau_{*_{c}}}{\tau_{*}}\right) \frac{1}{\left(\alpha-I_{f}\right) \cos \theta} G\left(I_{f}, \frac{h}{d}, \frac{w_{0}}{u_{*}}\right)
$$

where $s=(\sigma-\rho) / \rho ; \tau_{*}=$ the nondimensional shear stress; $\tau_{*_{c}}=$ the critical nondimensional shear stress; $\theta=$ bed slope angle; $I_{f}=$ the friction slope; $w_{0}=$ the fall velocity of sediment grains in water; $\alpha=0.875$ and $\bar{u}_{\delta} / u_{*}=4.7$.

According to Hashimoto et al. [9] \& [10], $G$ is a function of $I_{f}, h / d$ and $w_{0} / u_{*}$ and is approximated as

$$
G\left(I_{f}, \frac{h}{d}, \frac{w_{0}}{u_{*}}\right)=1+0.1\left(\ln \left(\frac{h}{d}\right)\right)^{2}\left(I_{f}\right)^{-0.8} \exp \left\{-2.5\left(\frac{w_{0}}{u_{*}}\right)^{0.5}\right\}
$$

We assume that river bed was composed of cohesionless sediments $2 \mathrm{~m}$ thick (Takahashi et al. [11]).

\subsection{Boundary condition}

The boundary conditions at $x=0$ (the landslide position) are given by

$$
Q=Q_{0}(t), h=\left(\frac{Q}{\phi B \sqrt{g \sin \theta_{0}}}\right)^{2 / 3} \text {, and } C_{T}=C_{0}
$$

for $0 \leq t \leq T$ and 


$$
Q=Q_{w 0}(t), h=\left(\frac{Q}{\phi B \sqrt{g \sin \theta_{0}}}\right)^{2 / 3}, \text { and } C_{T}=0
$$

for $T<t$.

Here $Q_{0}(t)=$ initial flow discharge and $C_{0}=$ initial sediment concentration and $T=$ landslide duration. The value of $C_{0}$ is assumed 0.5 . $Q_{w 0}(t)$ denotes flow discharge determined by runoff analysis. From the discussion of Chapter 2, we have

$$
Q_{0}(t)=\frac{V_{s}}{C_{0}} u(t)
$$

where the landslide sediment volume $V_{s}$ was estimated as $21,000 \mathrm{~m}^{3}$ by Kumamoto Prefectural Government and four kinds of response functions $u(t)$ is assumed, as shown in Fig. 4.

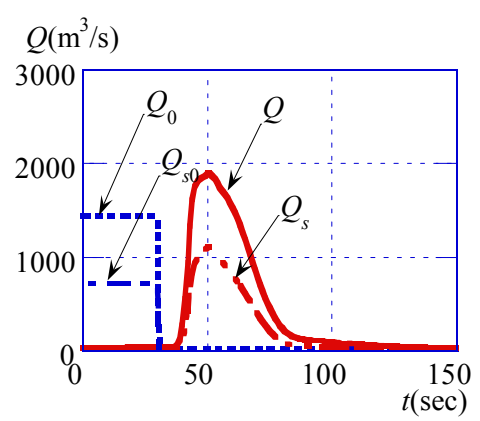

(a) Case A

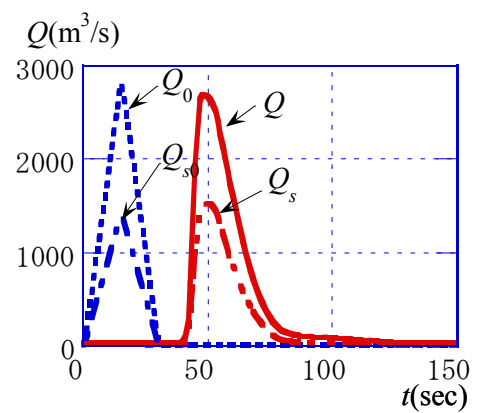

(c) Case C

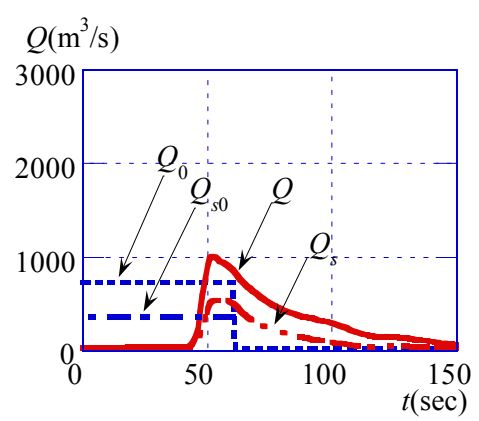

(b) Case B

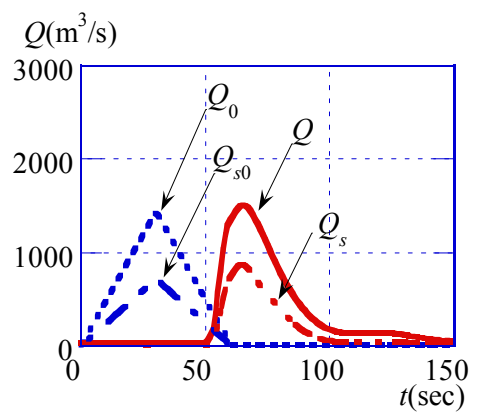

(d) Case D

Figure 6: Debris flow hydrograph assumed at the landslide position and calculated at the most downstream check dam.

\subsection{Prediction of debris-flow hydrograph}

Figs. 6 (a), (b), (c) and (d) show the discharge hydrograph calculated at the most downstream check dam in Case A, B C and D, respectively. We can find the peak discharge $1,000-2,500 \mathrm{~m}^{3} / \mathrm{s}$. The peak time is in 50 to 60 seconds after the initiation of landslide. Kumamoto Prefectural Government found the peak 
discharge $1,300-4,700 \mathrm{~m}^{3} / \mathrm{s}$. The calculation results agree with the investigation of Kumamoto Prefectural Government. When the different response functions have the same landslide duration, we can find the predicted peak discharge almost same. The total sediment outflow volume from the most downstream check dam is found $43,000 \mathrm{~m}^{3}$ from the calculation result. Kumamoto Prefectural Government found the sediment outflow volume $64,000 \mathrm{~m}^{3}$.

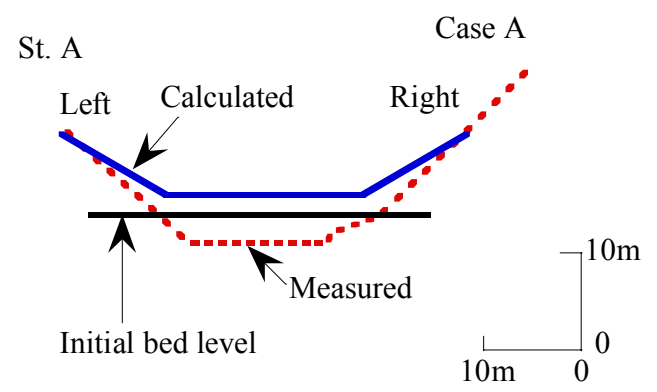

Figure 7: Comparison between measured and calculated channel cross section.

Fig. 7 shows the comparison of channel cross sections calculated and measured at St. A (fig. 2). The calculated channel width agrees with measured one. The calculation shows bed level increase, and measurement shows bed erosion. This is why initial sediment concentration $C_{0}=0.5$ becomes larger the equilibrium sediment concentration estimated with eqn (11).

\section{Two-dimensional debris flow simulation}

Two-dimensional debris flow simulation is made for the region from the most downstream check dam (fig. 2) to the confluence of the Atsumari and Hougawachi River. We select hydrograph calculated in Case A (fig. 6 (a)) as the boundary condition.

The initial river bed condition of the study area is dry. The boundary conditions at the check dam are given by fig. 6 (a). We simulate the debris flow behavior for the period of 300 seconds from the initiation of the debris flow to its termination.

Fig. 8 shows the plan view of the calculated flow depth. There are several houses on hills of both sides of the downstream reach. Position E indicates the river channel and Positions $\mathrm{F}$ and $\mathrm{G}$ indicate houses on the left-hand and righthand side of the river bank, respectively. The houses at positions $F$ and $G$ were broken by the debris flow. We find that the debris flow overflowed river bank near the village and inundated houses, especially on the bank of the right-hand side.

The deposited sediment volume is found $37,000 \mathrm{~m}^{3}$ from the calculation result. On the other hand, Kumamoto Prefectural Government found deposited sediment volume $53,000 \mathrm{~m}^{3}$. 


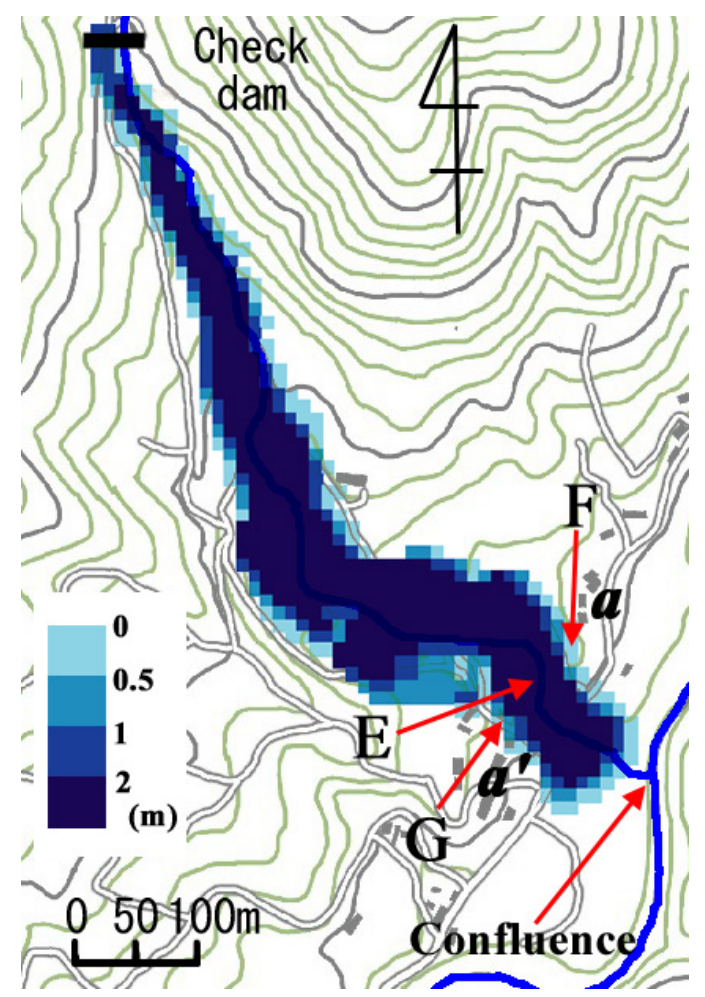

Figure 8: $\quad$ Flow depth calculated at $t=90 \mathrm{sec}$.

\section{Conclusions}

The results obtained in this study are as follows:

(1) The transformation of landslide into debris flow is expressed by some response functions. Landslide sediment volume can be regarded as the input of the system and sediment discharge as the output.

(2) Using the transformation model, we have predicted the debris outflow hydrograph from the middle river reach. The peak discharge of the debris outflow is found about $2,000 \mathrm{~m}^{3} / \mathrm{s}$.

(3) In the cases of same landslide duration, the peak discharge is almost same with different response functions. The peak discharge of debris flow depends on the duration of the landslide

\section{Acknowledgment}

This research has been supported by Grant-in Aid for Scientific Research, Japan Society for the Promotion of Science. The authors would like to appreciate their grant in aid on this research. 


\section{References}

[1] Nakagawa, H., Takahashi, T., Satofuka, Y., Tachikawa, Y., Ichikawa, Y., Yoshida, Y. \& Nakamura, Y., Debris Flow Disasters at the Harihara River, Izumi City, Kagoshima Prefecture, 1997. Disaster Prevention Research Institute Annuals, Kyoto Univ., No. 41 B-2, pp. 287-298, 1998 (in Japanese).

[2] Nakagawa, H., Takahashi, T. \& Satofuka, Y., A Debris-flow Disaster on the Fan of the Harihara River, Japan. Proc. of the $2^{\text {nd }}$ International Conference on Debris-Flow Hazards Mitigation: Mechanics, Prediction, and Assessment, pp. 193-201, 2000.

[3] Hashimoto, H., Park, K. \& Hirano, M., Numerical Simulation of SmallDischarge Debris-Flows at Mt. Unzendake Volcano, Japan. Proc. of the $2^{\text {nd }}$ International Conference on Debris-Flow Hazards Mitigation: Mechanics, Prediction, and Assessment, pp. 177-183, 2000.

[4] Park, K. \& Hashimoto, H., Runoff Analysis of Debris Flows at Mt. Unzendake Volcano, Japan. Proc. of the $3^{\text {rd }}$ International Conference on Debris-Flow Hazards Mitigation: Mechanics, Prediction, and Assessment, pp. 695-704, 2003.

[5] Satofuka, Y., Numerical Simulation of the Debris Flow at the Atsumari River, Minamata City, 2003. Annual Journal of Hydraulic Engineering, $J S C E$, Vol. 48, pp. 925-930, 2004 (in Japanese).

[6] Takaoka, H., Hashimoto, H., Park, K. \& Hisaoka, N., Bed and Bank Erosion Rate Equations for a Steep Mountain River. Proc. of the XXXI CONGRESS of IAHR, pp. 3131-3143, 2005.

[7] Takaoka, H., Hashimoto, H., Park, K., Kido, S. \& Hikida, M., Simulation of the Minamata Debris Flow Disaster in 2003. Proc. of the XXXI CONGRESS of IAHR, pp, 3144-3155, 2005.

[8] Takaoka, H., Hashimoto, H., Park, K., Ikematsu, S., Kido, S. \& Hikida, M., Peak Discharge of the Debris Flow in Minamata City on July 20, 2003. Proc. of the $2^{\text {nd }}$ Symposium on Sediment Disaster, pp. 103-108, 2004 (in Japanese).

[9] Hashimoto, H., Park, K., Ikematsu, S. \& Tasaki, N., A Sediment Discharge Formula for Various Types of Sediment Transport in a Steep Open Channel. Annual Journal of Hydraulic Engineering, JSCE, Vol.47. pp. 571-576, 2003 (in Japanese).

[10] Hashimoto, H., Takaoka, H. \& Park, K., Sediment Discharge Formula for Steep Open Channel. Proc. of the $9^{\text {th }}$ International Symposium on River Sedimentation, Vol. 3. pp. 1453-1461, 2004.

[11] Takahashi, T., Inoue, M., Nakagawa, H. \& Satofuka, Y., Prediction of Sediment Runoff from a Mountain Watershed. Annual Journal of Hydraulic Engineering, JSCE, Vol. 44. pp. 717-722, 2000 (in Japanese). 